\title{
Overcoming the Last-Mile Problem with Transportation and Land-Use Improvements: An Agent-Based Approach
}

\author{
Moira Zellner ${ }^{1}$, Dean Massey ${ }^{2}$, Yoram Shiftan ${ }^{3}$, Jonathan Levine ${ }^{4}$ \\ and Maria Josefa Arquero ${ }^{5}$ \\ ${ }^{1,2}$ University of Illinois at Chicago \\ ${ }^{3}$ Technion University \\ ${ }^{4,5}$ University of Michigan \\ 1mzellner@uic.edu,2dmasse2@uic.edu,3shiftan@technion.ac.il, \\ ${ }^{4}$ jnthnlvn@umich.edu, ${ }^{5}$ marquero@umich.edu
}

\begin{abstract}
Transit in the United States often suffers from the problem of inability to deliver travelers all the way from their point of origin to their destination. This "last-mile" problem is thought to deter transit use among riders with auto access, even when highquality transit service is provided for the majority of the trip distance. This study explores how transportation improvements, including automated driverless shuttles between origins of trips and nearby transit stations, and physical improvements enhancing pedestrians' and cyclists' commute might help overcome the last-mile problem particularly as they interact with policy shifts including changing in parking and fuel costs. To conduct this study, we developed an agent-based model representing the commuters and their preferences for different aspects of transportation disutility, namely cost, time and safety. Commuters in the model assess their transportation options in light of their preferences, the characteristics of their environment, and the various modes available to them. The model is calibrated with data from four Chicago neighborhoods, representing four different combinations of land-use patterns and household income. Simulations suggest significant potential for the combined shuttles and urban design improvements to shift downtown commuters to non-automotive modes (between 12 and 21 percentage point reduction in driving in three out of four neighborhoods). Less dense neighborhoods were more sensitive to higher parking costs, streetscape improvements and shuttle service than the denser and more pedestrian-oriented neighborhoods. Distance from the station encouraged driving, but the presence of shuttles encouraged shifts towards transit. Streetscape improvements tended to support transit use closer to train stations. In addition to anticipating a range of likely mode choice outcomes, the agent-based modeling approach facilitates exploration of the mechanism underlying travelers' behavior. Rather than modeling through data fitting, our approach involved formulating theory of behavior first, using data to parameterize the conceptual model, and running simulations to see how the outputs would match observations. When discrepancies arose, we advanced the theory and reformulated the conceptual model to explain them. In this way, we found that a dense bus service shuttling travelers towards the commuter train station with express service downtown was critical in encouraging transit use, and extensive bus coverage throughout another neighborhood encouraged bus use to access downtown. Bike penalties representing various difficulties inherent to this mode (e.g., lack of physical fitness, the need for showering facilities at the destination, etc.) needed to be adjusted to higher values than those typically found in the literature, suggesting greater barriers to biking in this metropolitan area. Finally, we had hypothesized that pedestrian and biker presence would represent an important feedback promoting shifts away from driving, but this was not the case. Further in-depth empirical
\end{abstract}


research is needed to improve our conceptual models of this feedback, and to understand how policy can leverage it to encourage greater transit, pedestrian and bicycle use.

Keywords: last-mile problem, agent-based modeling, mode choice, automated transit vehicles

\section{Introduction}

Rapid progress in automated vehicle technology over the last few years opens up the possibility of novel transportation alternatives. The car that drives itself-once a futuristic vision but currently under development in a number of forms - can offer numerous safety, societal, and infrastructure-related advantages. But the transformative power of rapid technological advances need not be restricted to private transportation and can alter people's choices of modes, destinations, and even locations. One potential domain of this transformation is in the "Last-Mile Problem" of public transit [1] whereby access to and from high-quality transitreferred to as "the last mile" - strongly shapes people's propensity to use the transit mode. Transit that offers frequent and rapid service along the main lines but leaves the travelers a mile from their destinations with poor connecting options is rarely the mode of choice.

Cost is always a significant obstacle to overcoming the "last-mile" problem. In low-to-medium density environments in particular, the cost of providing connecting service may not be shared across a high number of passengers because of low vehicle occupancies; this renders the cost per passenger unaffordable, whether in the form of high fares or unsupportable subsidies. A majority of the operating costs of public transit are the cost of wages and benefits [2]; technological innovations that can reduce transit labor intensiveness therefore hold potential to expand transit's reach by lowering its per passenger cost. In addition, work rules frequently require or prioritize day-long shifts for drivers, leading to high labor costs that continue even during periods of low transit demand.

In combination, these ideas-automated vehicles, high labor costs for transit, and avoiding operating costs during periods of low transit demand-suggest an approach to the perennial "last-mile" problem: automated shuttles to provide services between neighborhoods and rapid transit stations. The potential for these vehicles to operate without drivers may significantly lower their operating costs, thus enabling frequent demand-tailored service that better serves travelers' needs.

The vision of frequent driverless shuttles linking neighborhoods and rapid transit is undoubtedly a long way off and would require significant research and development work, some of which would need to start early on. As appealing as it may appear to some, the vision is not self-justifying, however. It may be that in most U.S. contexts, even a high level of shuttle service connecting neighborhoods to rapid transit would be insufficient to alter the travel choices of a significant number of travelers. Alternatively, streetscape improvements or rising driving costs, which have been more extensively covered in the literature (e.g., [3]), may provide stronger incentives for modal shifts. For example, the success of transit depends in large part on its broader urban environment, since every transit trip begins and ends as a walking trip. Improved streetscape aesthetics, increased density and mixing of land uses, and presence of sidewalk walkers enhance the attractiveness of walking as a mode of transportation $[4,5]$ and to bus ridership [6, 7]. For many people, the bicycle can provide a fast commute to work but is frequently hampered by unappealing or unsafe bicycle facilities. Establishing bike facilities, lanes and paths can result in higher bike use, more so if lanes are separate from the street $[8,9]$. 
We present here an initial inquiry into the relative impact of approaches to the last-mile problem based in automated neighborhood shuttles, pedestrian improvements, and cycling enhancements, with the intent of informing discussions on policy choices with regard to these options. Because investments in automated vehicle technology are long-term in nature and somewhat speculative at this point, this research is intended as an initial inquiry into the capacity of this technology, when deployed as neighborhood shuttles, to encourage shifts away from the drivealone mode. For this reason, this research has been structured as a "best-case" scenario for these technologies (i.e., without congestion, limitations of right of ways, or weather); the idea is to aid in an assessment of whether or not they hold promise for further research and development rather than a narrow feasibility assessment. In order to model this best-case scenario, the analysis included modifications in the transit environment that would give the greatest chance of yielding significant shifts in travelers' modes. below).

\subsection{Mode Choice Modeling and the Last-Mile Problem}

To be able to explore scenarios that do not yet exist, we relied on simulation modeling. To this end, we built a prototype agent-based model of commuters living within 1.5 miles $(2.4 \mathrm{~km})$ from a transit station in their neighborhood. We focused on commuters for whom transit is a feasible and attractive choice because they also work or study in the downtown area. While access to transportation choices might exist to other destinations, more detailed data typically exists for downtown commutes, providing a good case for an initial exploration. The neighborhoods modeled are part of a larger metropolitan area, which is not explicitly represented but is inferred in the time it takes commuters to get downtown. Commuters have a choice of various transportation modes to travel to work, and their decision is based on their preference for travel time, transportation cost, and perceived safety. The neighborhood landscape fabric, parameters and mechanisms of commuting behavior are modeled after four neighborhoods in the Chicago metropolitan area in Illinois, USA, which experiences fairly low transit ridership (5.1\% bus, $4.7 \%$ local train, and $5.7 \%$ commuter train [10]) despite its relatively high-quality service. The four neighborhoods vary along two important dimensions influencing mode choice: landuse composition (low-density and primarily residential use versus higher density and mixed use), and income level (lower versus higher).

Transportation mode choice is most typically modeled using discrete choice models (e.g., logit models), based on Random Utility Theory. This modeling approach involves estimating the utility function for each available mode, which requires choosing variables to be included in the utility function and its functional form (which is usually linear), and estimating the parameter values with maximumlikelihood estimation. Household survey data and data from transportation network analyses are usually used to estimate these utility functions reflecting travelers' preference of modes. Recent advances in travel demand modeling has expanded this approach to activity-based modeling, where the demand for travel is derived from the demand for activities. The activity-based approach is used to estimate the individuals' entire daily activity pattern, including activities in which the individual participates, the timing and location of these activities, and the mode the individual takes to travel to and between these activities. When data are not available because of the hypothetical or speculative nature of the choices, or when interactions among commuters and their environment affect travel decisions iteratively, the traditional approaches are limited in exploring potential outcomes. These limitations led this research to an iterative agent-based approach while structuring utilities of modes and probabilities of their selection according to the traditional logit model. Specifically, we sought to build in the potential for a feedback loop to influence 
commuters' mode choices over time: in a number of circumstances, individuals' propensity to select a mode may be motivated by their observation of others choosing that mode, in part due to people's perceptions of safety.

Agent-based models have been used in a variety of urban transportation studies, and particularly to examine the link between land use and transportation behavior e.g.,[11-15]. These computational models feature agents as commuters whose attributes (e.g., income level, vehicle ownership) influence their transportation preferences (e.g., how much they value monetary cost) and thus influence mode selection. Agents may interact with each other and with the various transportation modes and/or the pedestrian environment, affecting each other's choices. Relevant interactions in our model include responses to pedestrian and bike traffic as they evolve over time, triggered by streetscape quality and transit options that improve neighborhoods' pedestrian and biking environment. Congestion and infrastructure capacity is the focus of many studies. By contrast, our model focuses on the adoption of alternative modes over short distances to the rail station, where congestion would not significantly influence the time of the trip. (Congestion in our model influences mode choice in the travel time assumed for each mode outside of the neighborhood.) We used the model to explicitly represent assumptions about mode choice where data are absent because the transit environment we envision does not yet exist. We thus started with a theoretical rather than a data fitting modeling process. We used data to compare simulation results to observed mode share patterns as reported by transportation agencies, and in this way determine if our theory was enough to explain existing mode shares in the various neighborhoods. As we encountered discrepancies, we advanced the theory by reformulating the model with possible explanatory mechanisms for the differences. Once we matched observations, we used the model to examine how different transit improvement scenarios might fare against each other and to identify important factors that may influence the results. In particular, we sought to illustrate how supportive public policies (e.g., increasing driving or parking costs) in combination with the physical improvements may alter the potential of the transformative transportation vision. Our model is not designed as an accurate forecasting tool but rather as in initial test of the high-end potential of such new approach to improve transit use.

In the following sections, we describe the details of our model, followed by a discussion of the simulations and insights derived from the scenarios tested. We conclude with implications for policy and directions for future work, including the analysis of ongoing empirical data collection and recommendations for future empirical research.

\section{The Model}

We built our agent-based model using Netlogo [16], representing commuter agents choosing a mode that minimizes the disutility of their trip, with the variables comprising their utility function being monetary cost, time, and safety. In this section we describe the model's agents and landscape, their attributes, and the decision rules by which they interact and change. We model our agents and environment after four neighborhoods in the Chicago Metropolitan Region with access to a train station of the Chicago Transit Authority (CTA) system. The neighborhoods represent combinations of two important factors in mode choice: land-use mix and density, which is also strongly associated with the transit type and level of service provided, and income. The neighborhoods are (Figure 1): (1) Evanston (higher income, higher-density mixed use) at the Davis station, (2) Skokie (higher income, lower-density single use) at the Dempster-Skokie station, (3) Cicero 
(lower income, lower-density single use) at the $54^{\text {th }} /$ Cermak station, and (4) Pilsen (lower income, higher-density mixed use) at the Damen station.

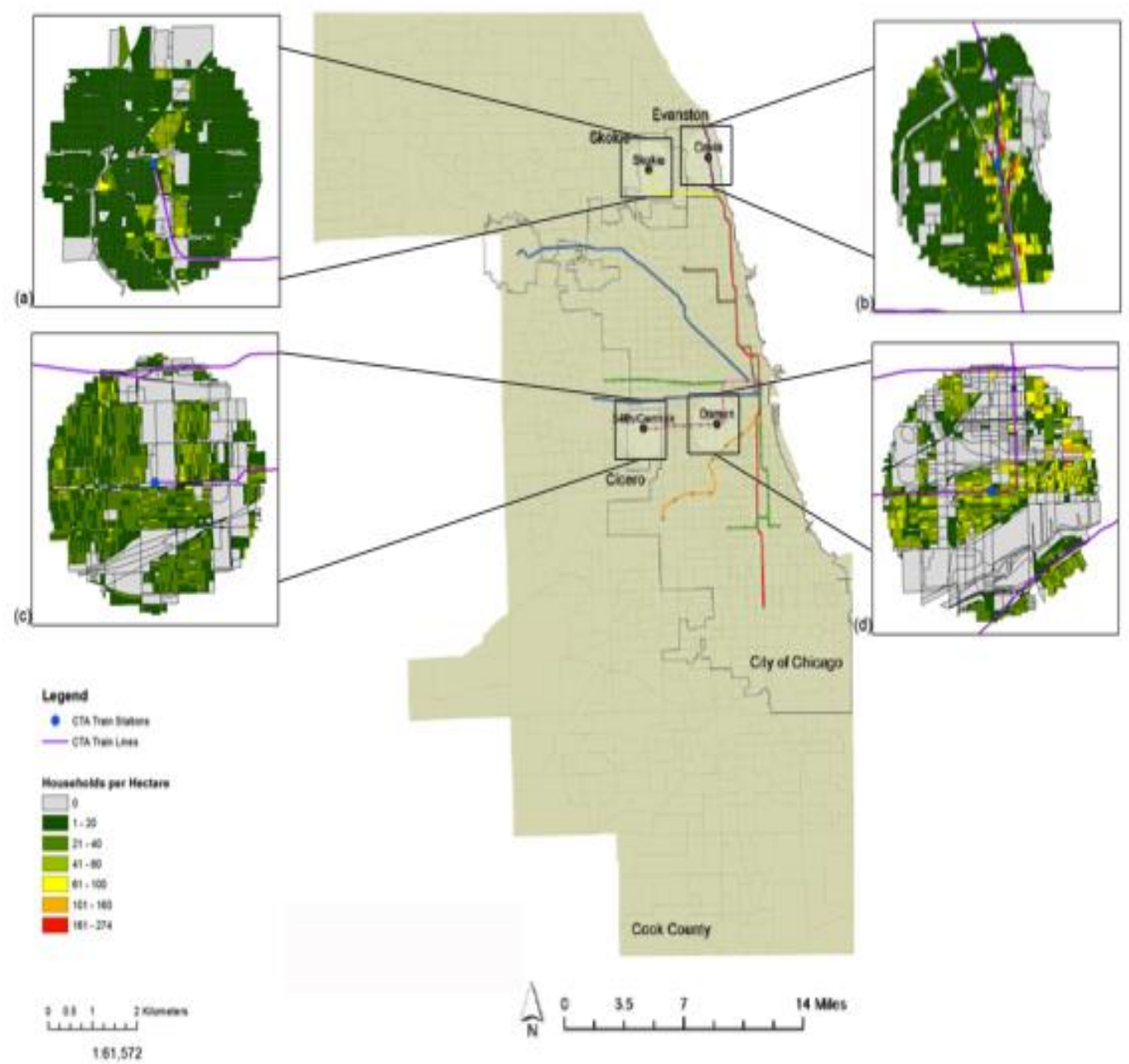

\section{Figure 1. Location of the Four Chicago Neighborhoods: Evanston, Skokie, Cicero and Pilsen. CTA Train Network in Color}

Our model represents six modes: (1) walk to train, (2) bike to destination, (3) bike to train, (4) bus to destination, (5) drive to destination, and (6) shuttle to train. We excluded other modes (e.g., carpooling or driving to station) because they would increase the computational complexity of the model without adding insight into our question of how shuttles would support transit and encourage commuters to shift from driving all the way to work. Other modes are also variations on the six we implemented; in the case of carpooling, for example, driving all the way to work would be a close approximation. All modes reflect frequencies and commute times for travel to work and school in the Chicago "Loop" during morning rush hour.

The model is informed by the literature and publicly available data on commuter behavior, land use, and transit service, and commuters' preferences for different aspects of transportation (summarized in Table 1, and detailed in each section below). A parallel effort to survey commuters in our four target neighborhoods has been completed. The next stage of the project is to inform our model with response 
data to test the robustness of the insights we derive here and to provide more specific policy recommendations. At this stage of our research, the model provides estimates of impacts under the best circumstances that can be generalized to a range of conditions, and generates questions to address with a future data-based version of our model.

\section{Environment}

\subsection{Neighborhood Landscape}

Our model has a landscape that is a two-dimensional square grid with a street network centered on a train station. Each neighborhood represents the area that is within walking and biking distance of a particular CTA train station (a radius of 1.5 miles or $2.4 \mathrm{~km}$ ). Each neighborhood is defined by a select number of factors that differentiate the neighborhoods' physical layout (Table 1). In the case of Evanston, the proximity to Lake Michigan locates over one-quarter of the 1.5-mile-radius circle in water; to reflect this in the model, this area is blank and impassable. Each individual land parcel occupies one cell in the lattice, and together the parcels form blocks. We used the median lot width and block dimensions derived from an analysis of a dataset of lots provided by Cook County [17] for each neighborhood to define the corresponding cell size and block size in the model (Table 1). We use median, rather than average, values to reduce distortion introduced by other land cover types with significantly larger lots (e.g., industrial). The simulated urban block includes the sidewalk (one cell wide) in addition to residential parcels. Every block is surrounded by streets that are one cell wide (Figure 2). To mirror a street network with wider arterials, every fourth street is two cells wide, with spacing centered so the streets that lead to the train stations are arterials. A line of cells cutting horizontally through the middle of a block simulates alleyways, which are present in almost every block in Chicago and its environs. Alleys are public spaces that cannot be built on, and representing them in our model allows us to account for this additional space (Figure 2).
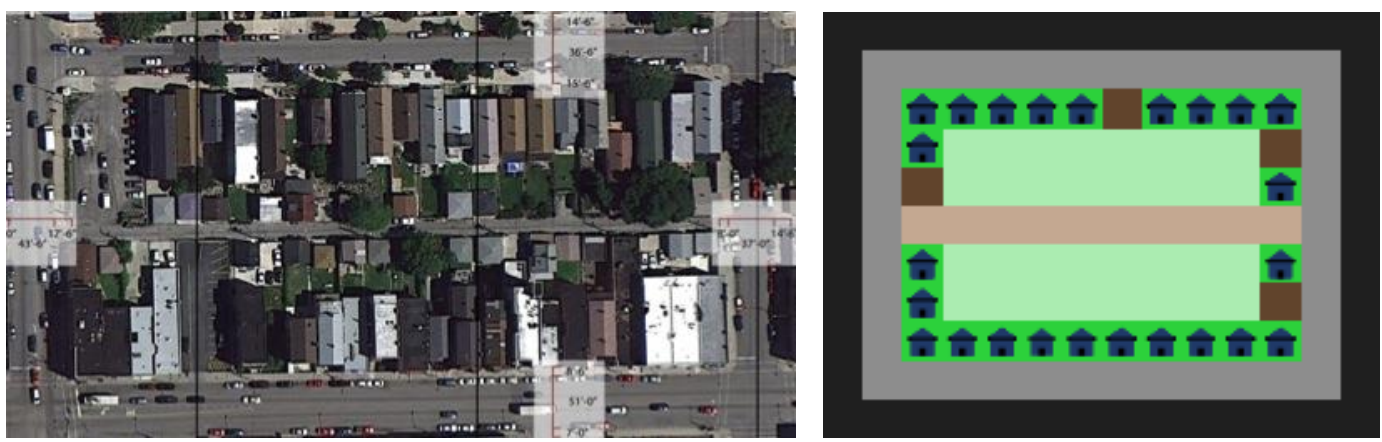

\section{Figure 2. Sample Block in Pilsen and a Generic Modeled Block. Households in Blue, Roads in Black, Sidewalks in Grey, Vacant Lots in Dark Brown, Alleys in Beige}

Households may be located only on block cells that border sidewalks and are not covered by alleys. These cells are assigned a random number of households drawn from a truncated normal distribution $[18,10]$ to recreate approximate densities in each neighborhood. In Evanston, approximately one-third of the entire area population lives within half a mile of the Davis station (10\% of the land area). Due to this difference with the other three neighborhoods, the model randomly populates the landscape adjacent to the station with densities higher than those further away 
from the station (Table 1). Skokie and Evanston have a fairly continuous urban fabric with small areas dedicated to non-residential uses, whereas Cicero and Pilsen have larger industrial sites that break up the residential areas (Figure 1). Overall, $39 \%$ of the Cicero neighborhood is unoccupied, devoted to industrial and infrastructural uses, and has only arterials roads. In Pilsen, $60 \%$ of the landscape is unoccupied, traversed only by arterial roads. To reflect these differences among the four neighborhoods, our model assigns non-residential lots randomly in Skokie and Evanston, but recreates large non-residential areas, and the corresponding street network distortion, in Cicero and Pilsen (Figure 4, Table 1).

(a)
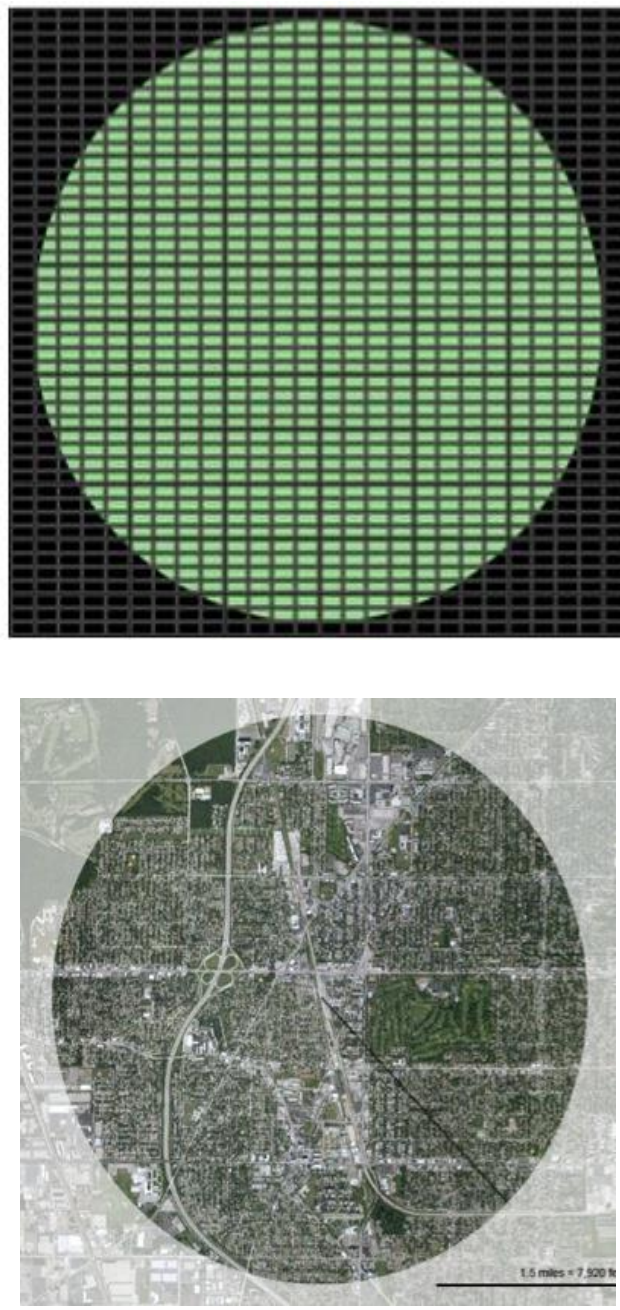

(c)

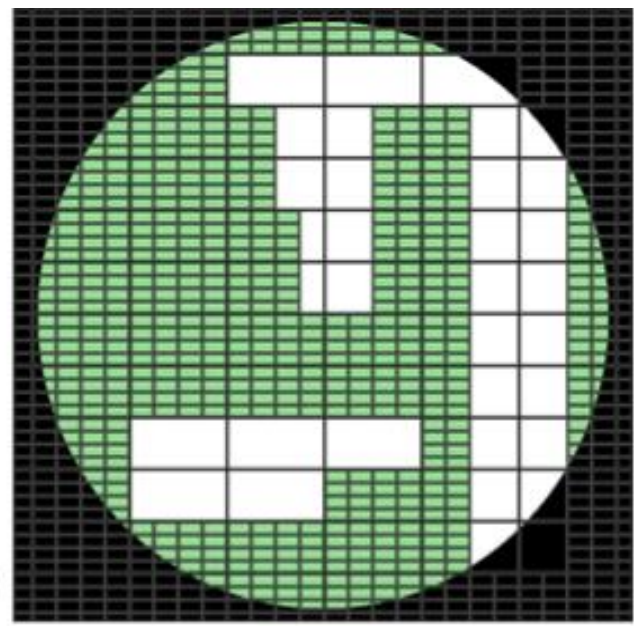

(b)
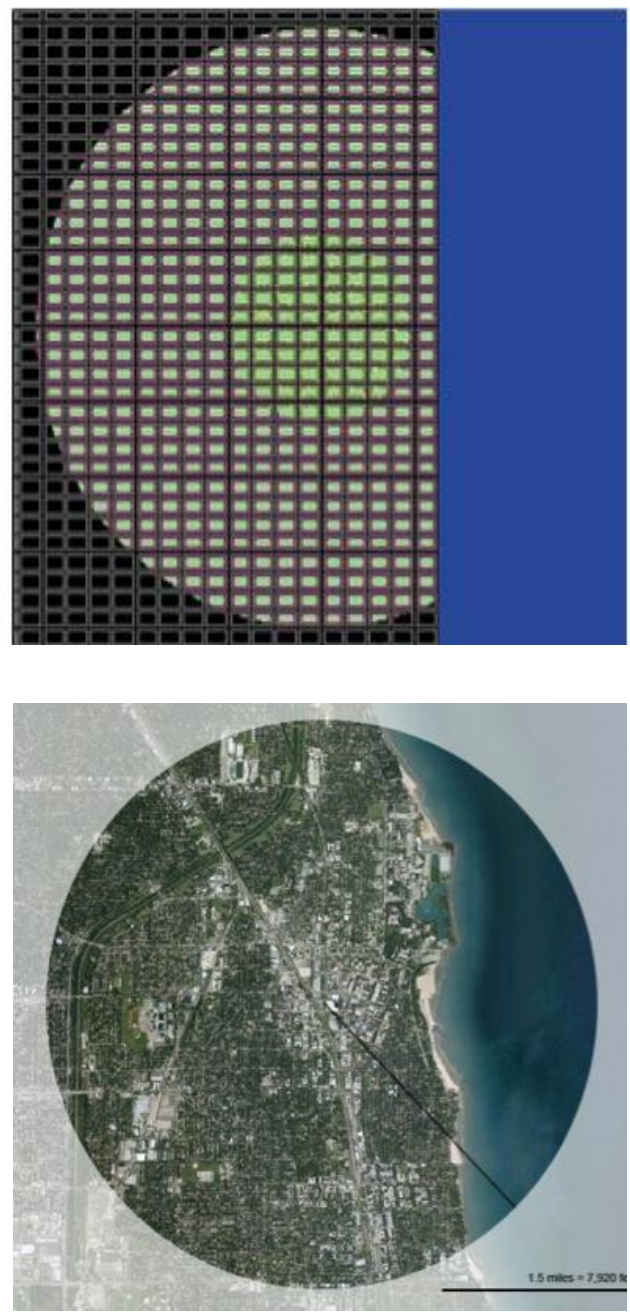

(d)

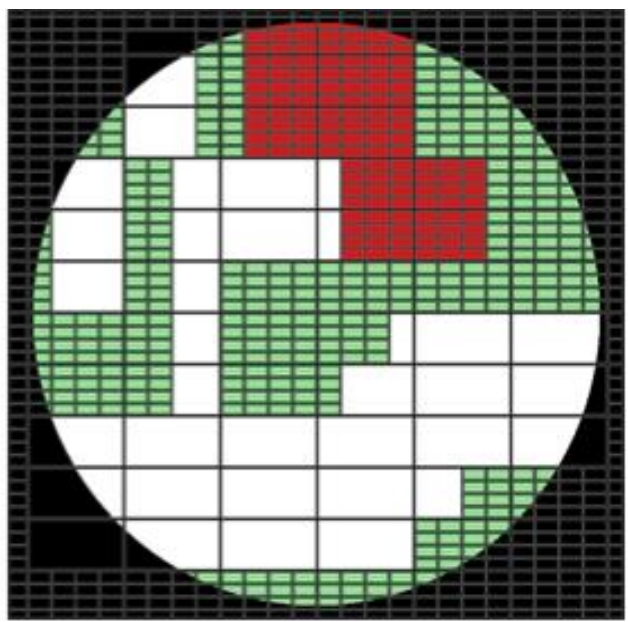



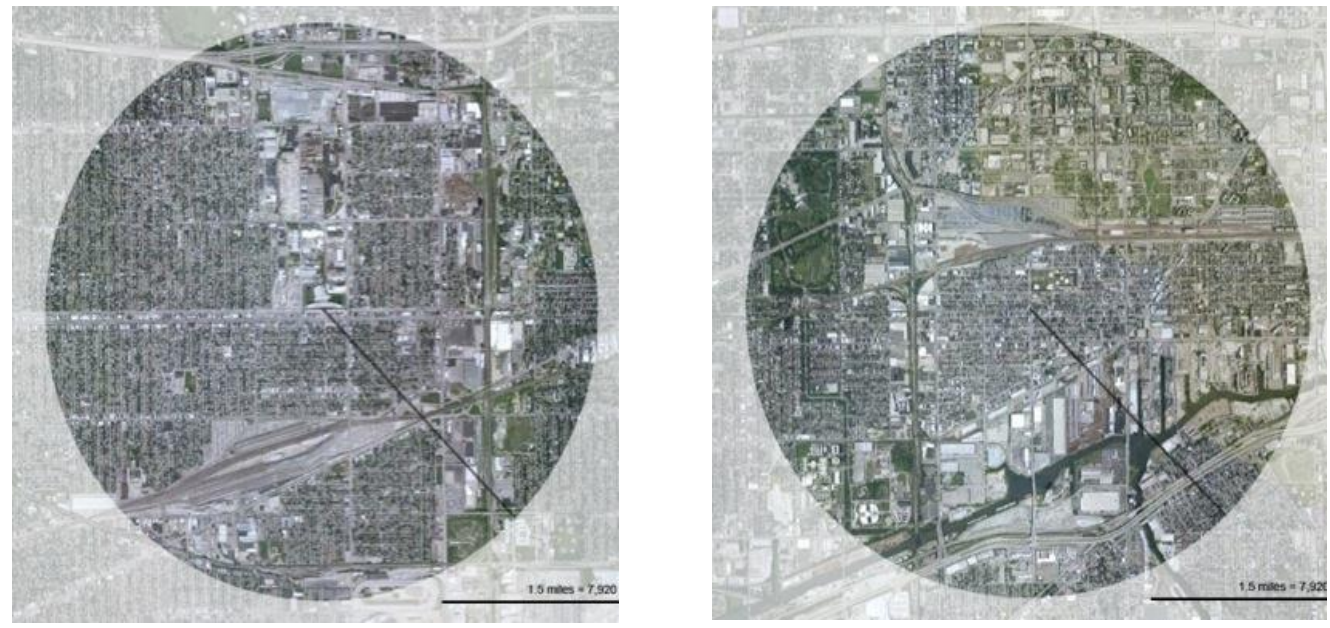

\section{Figure 3: Simulated Landscape (and Corresponding Aerial Photos) for (a) Skokie, (b) Evanston, (c) Cicero, (d) Pilsen. Residential Areas in Green, Industrial Areas in White, Commercial Areas in Red, Low Density Areas Outlined in Purple (Evanston), Lake Michigan in Blue (Evanston)}

3.1.1. Travel Setup: Although the model generates all commuting households, only a fraction of these households commute to the inner central area of Chicago, the central business district that contains the area known as the Loop. Each household is assumed to have one downtown commuter. When the model generates the households, it randomly decides which households will have commuters who travel to the Loop and which will travel to other areas in the Chicago region. Non-Loop commuters are randomly assigned a mode of travel based on current mode shares [10], and will not change their travel mode during a simulation. The purpose of these simulated trips is to provide background traffic that can affect the decision-making of the Loop commuters through perceptions of safety based on pedestrian and biking traffic (Section 0).

Each neighborhood has four exit points where the 1.5-mile radius intersects the main arterials. The exit closest to the Loop is the one that drivers and cyclists take in their downtown commute, while the three others connect them to non-Loop destinations.

Times, speeds, and transfers for transit for Loop commuters were estimated using goroo.com [19], a site operated by Chicago's regional transit agency; driving and biking estimates were from Google Maps [20]. Speeds for all modes are average speeds, which include traffic signals, congestion during rush hour, and transit stops. Bus and train headways were estimated using published schedules [21]. Train fare in all neighborhoods was $\$ 2.25$ [21]. Bus fares vary with the number of transfers. The fare for Pilsen, Cicero, and Skokie was set at $\$ 2.25$ based on the published fare charts [21]. The fare was higher in Skokie because of service provided by PACE, the suburban bus authority [22]. Although PACE also serves locations in Cicero and Evanston, CTA buses provided the commute with the shortest overall time to the Loop.

Train layout: In Chicago, the train station entrances are either at or near street intersections. Train stations in our model are thus located on a street intersection at the center of the simulated landscape. In denser areas like Pilsen and Evanston, more than one station may be found within the neighborhood. For the purposes of comparability across neighborhoods to address the last-mile problem, we selected the station at the center of the 1.5-mile radius and excluded any other stations that might have been covered in the same area.

Buses: Although more than two lines typically run through each neighborhood, only a few lines take commuters to the Loop with one transfer or less, and they tend to run close 
to the CTA stations. We thus model two bus lines in each neighborhood running north to south and west to east on the arterials that go through the middle of the neighborhood (Table 1, Figure 4), within two blocks of each station, and with stops spaced every two blocks, the typical spacing in Chicago [23]. We assume buses have no capacity constraints, meaning that buses can meet transit demand without limit. This assumption stems from the problem definition of representing a best-case scenario for transit use.

Shuttles: This study is designed primarily to evaluate the impact of a form of transit that does not yet exist: a driverless neighborhood shuttle that would run frequently during rush hour and transport commuters to and from the train station. When this option is active in the model, the service runs every three minutes from the four corners of the neighborhood towards the station (Figure 4), picking up commuters at each stop along the way (except in Evanston, where shuttles only run through the land area). This layout minimizes duplication with bus routes. We expect that households furthest from the CTA station would have a stronger incentive to take transit than those more close by, because the ten-minute maximum travel time including waits provides a significant advantage to shuttle users towards the edge of the 1.5 mile periphery. The shuttle is free of cost, so the monetary cost of the trip using a shuttle to get to the train and then taking the train to the Loop is only the train fare (Table 1).

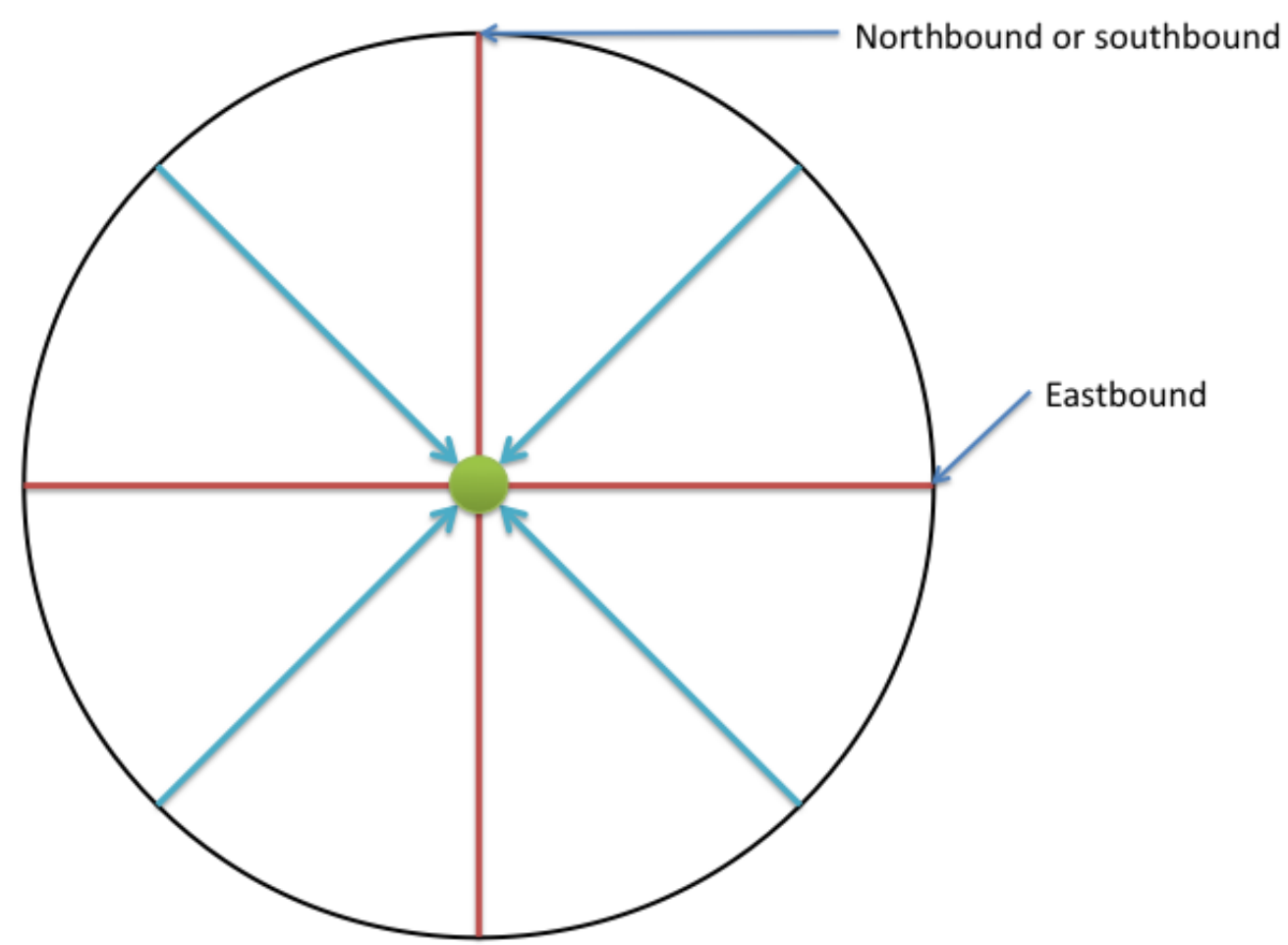

Figure 4. Conceptual Bus and Shuttle Network. Bus Lines in Blue, Shuttle Lines in Red, CTA Station in Green

\subsection{Commuter Agents}

As mentioned earlier, our model assumes one commuter (agent i) per household traveling for their primary activity of the day, defined as the work or school commute downtown. Commuter agents are heterogeneous. They are randomly assigned a unique set of attributes that influence their mode choice: automobile and bike ownership, parking cost at the destination, location within the neighborhood, and departure time. In the current version of the model, attributes are independent of each other. Empirical data 
collection will allow us to establish relationships among these attributes to create typologies of agents.

Household bike availability is fixed at $56 \%$ across all neighborhoods, corresponding to data for the National Highway Traffic Safety Administration region that includes Illinois [24], Table 1. Neighborhood-specific automobile ownership data are readily available from the Federal Highway Administration [25], Table 1. Car owners are assigned a parking cost value drawn randomly from a normal distribution derived from the average daily parking rate in the Loop [26] and a standard deviation based on an informal survey of 2011 parking garage rates in the Loop (Table 1). Departure times are drawn from a normal distribution over a 120-minute rush hour period, with the mean at 60 minutes (i.e., the middle of the rush hour period) and a standard deviation of 12 minutes. Times are rounded to the nearest minute.

Agents are assigned preferences or weights for each aspect of utility derived from different aspects of their travel mode [27] Table 7.3; [28] Table 4.8: monetary cost (wm,i), in-vehicle commuting time (wt, $, \mathrm{x}, \mathrm{i})$ and out-of-vehicle commuting time (wt,o,x,i) for a particular mode $\mathrm{x}$, and safety (ws,i). Agents then use these preferences and assigned travel attributes (e.g., parking cost, travel times, etc.,) to calculate the (dis)utility for each mode choice $\mathrm{x}$ (ux,i). Based on these estimates, they choose the mode that renders the highest utility (or lowest disutility) for their commute. During their commute, agents gather information that will feed into their utility estimates at subsequent time steps in the simulation. The following section describes the order of events within a simulation, including the details for the utility calculation.

\subsection{Processes and Order of Events}

The model creates a new bus at the frequency established by the headway parameter. At each time step, households with a departure time corresponding to the time step start a new trip. Non-loop commuters travel by the mode assigned at setup. Loop commuters choose a mode based on the probabilities computed from the utilities derived from the available modes (section 0). Agents that choose a mode involving walking move to a sidewalk cell in front of their house; those biking or driving move to a road cell in front of the house. Loop commuters in transit will record how many other pedestrians and cyclists are in their vicinity, updating their perceived-safety score (section 0). We assume that agents will perceive a friendlier environment with greater street activity from non-drivers. Driving agents advance one cell per time step, while all other agents advance a portion of this distance, proportional to the speed of each mode (Table 1). The number of minutes each time step represents is a function of the block sizes in each neighborhood (Table 1). Agents and transit vehicles determine where to move based on a way-finding algorithm described in section 0 . The simulation ends when the rush hour period is over and all agents have reached their destination. Then, agents reset variables and store data about the previous trip. The simulation continues into the next day, and information about the number of non-driving agents encountered feeds back into the new day's mode choice. Each run lasts ten days, well after mode share has settled into a stable pattern.

3.3.1. Mode (dis)utility: The model uses a logit framework to estimate the utility of mode $\mathrm{x}$ to each commuter $\mathrm{i}$, ux, $\mathrm{i}$ (see equation 3 below). Probabilities of each commuter i taking mode $\mathrm{x}$ are then calculated from these utilities (equation 4). In all cases, the total utility of the trip (which does not include the benefits of accessing the destination) is negative, meaning that agents seek to minimize the disutility of their travel.

The money score $(\mathrm{mx}, \mathrm{i})$ is the monetary cost of taking mode $\mathrm{x}$ in dollars. For driving, gas is assumed at $\$ 4$ per gallon, and fuel efficiency at $22.6 \mathrm{mpg}$ [29]. In addition to gas, driving costs also include parking. For bus and train, monetary costs only include the corresponding fares. Other modes are free (Table 1). 
Times are estimated in minutes for agent $\mathrm{i}$ using mode $\mathrm{x}$, accounting for both in-vehicle $(\mathrm{tv}, \mathrm{x}, \mathrm{i})$ and out-of-vehicle time (to,x,i). Times are calculated using distances unique to the agents' location in the neighborhoods and average speeds listed on Table 1. Driving times are measured from when agents leave their houses and reach the center of Loop (the intersection of State Street and Madison Street in Chicago, which is the center of the city's grid system). Bicycling times are measured the same way as driving, but five minutes are added to the actual commute time to represent time spent taking bikes in and out of storage areas. Bus times are calculated measured from the moment agents board a bus at the closest bus stop to their houses to when they reach the center of the Loop. Train time is measured from the moment when agents board a train at the neighborhood station to when they reach the center of the Loop. Out-of-vehicle time is measured from when agents leave their houses to when they reach a transit stop for mode $\mathrm{x}$ and the time they spend waiting to board the transit vehicle and for each transfer, estimated as half of the headway time for that mode. A transfer penalty of five minutes per transfer is added to out-of-vehicle time beyond the actual time the transfer takes to represent the inconvenience of transferring modes [30,31]. We do not consider congestion or transit delays within the neighborhood, since we are modeling the best situation for alternative transportation.

The final component of utility is safety (sx,i), i.e., how agent i perceives the built environment being welcoming to walking or biking. We assume that the presence of other pedestrians and cyclists will reduce the perception of risk for these modes, in an attempt to operationalize the concept of "eyes on the street" [32,33]. Since we are modeling optimal conditions, we do not consider the effect of poor weather on perceived safety. We assume drivers are not affected by the built environment, given that they are not directly exposed to it; thus the safety score for driving is always 0 . For all other modes the score is composed of three parts, weighted equally (due to lack of data), and all ranging between 0 and 1 , where the smaller the score the higher the perception of safety:

$$
s_{x, i}=\frac{l+f_{i, t 1}+d_{x, i}}{3}
$$

Where:

$l=$ streetscape improvement level;

$f_{i, t-1}=$ presence of other pedestrians or cyclists in on the previous day, and

$d_{x, i}=$ duration of exposure to the built environment with mode $x$.

The streetscape improvements $(l)$ apply equally to all agents, and define a policy scenario (see Section 0). A value of 1 represents the current conditions (e.g., Figure 7a), 0.5 represents some improvements (e.g., Figure 7b), and 0 (e.g., Figure 7c) represents the ideal level of streetscape environment. The score for pedestrian/biker presence $\left(f_{i, t-1}\right)$ is initialized as 1 at the start of the simulation, and decreases over the course of the run as the encounters with other pedestrians feed back into the decision each day (see Section 0). Waiting for transit, walking or cycling all increase the exposure to the built environment. Longer times spent in these activities are associated with lower perceptions of safety. Perceptions of environment safety can be improved with streetscape improvements and/or pedestrian and biker presence, represented in equation 1. To obtain a score for $d_{x, i}$ that enables comparisons across factors, time is normalized with respect to the range of exposure times in all modes. Overall, the safety score component can range from 0 (maximum safety) to 1 (minimum safety). 

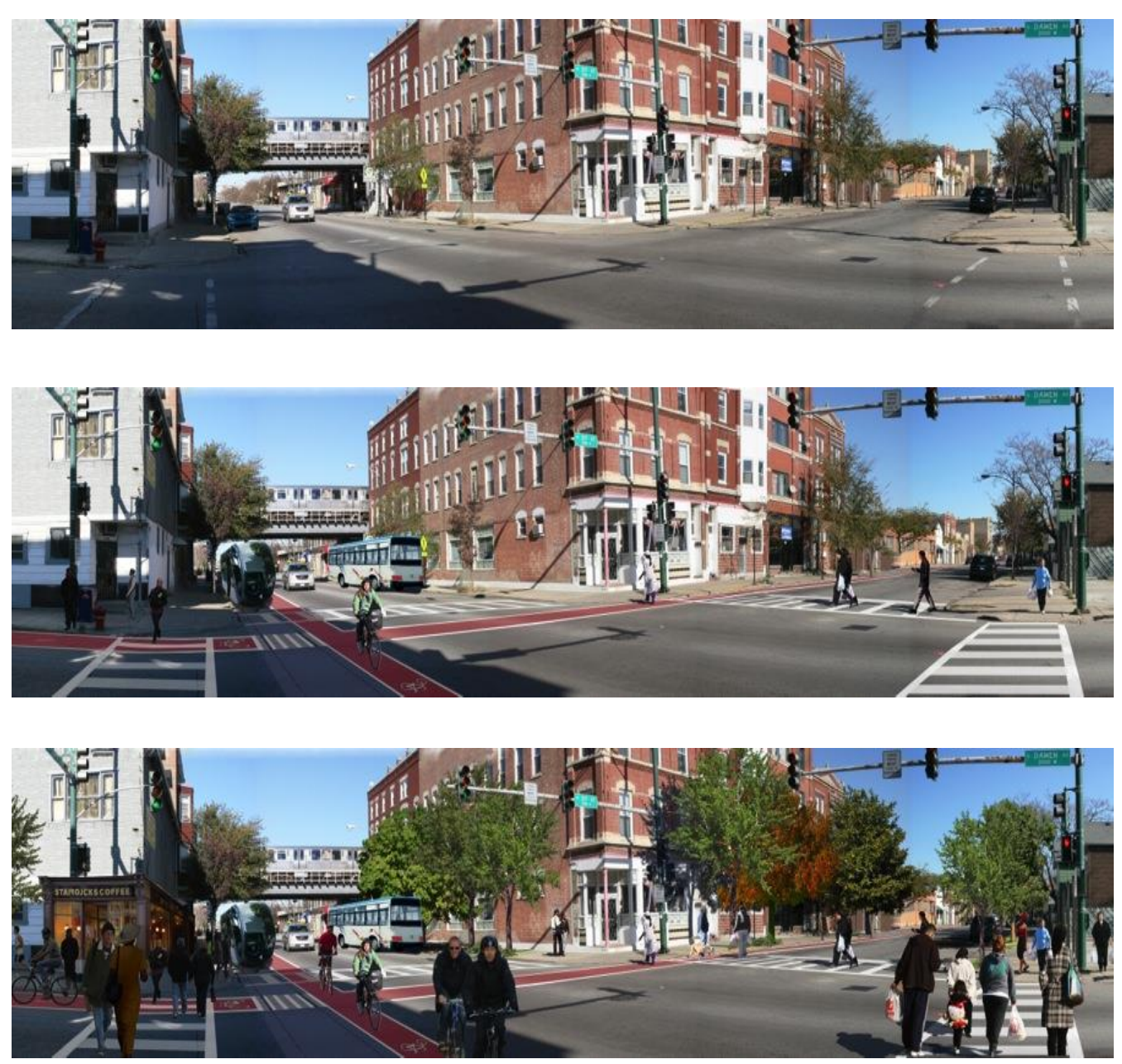

Figure 5. Streetscape Conditions: (a) Current; (b) some Improvement and Pedestrian and Cyclist Presence, and (c) Ideal Level of Improvements with Higher Pedestrian and Cyclist Presence

Commuter agents compute the utility they would derive from each mode $x$ by calculating the average of the raw scores for each dimension (money, times, and safety), weighted by agents' normalized preference for each dimension, based on a review of studies of US metropolitan areas (Table 1):

$$
u_{x, i}=w_{t, v, x, i} \quad t_{v, x, i}+w_{t, o, x, i} \quad t_{o, x, i}+w_{m, i} \quad m_{x, i}+w_{s, i} \quad s_{x, i}
$$

Commuters use the utilities for each mode to compute the probability of choosing mode $x\left(p_{x, i}\right)$ over all modes, as in traditional mode choice logit models:

$$
p_{x, i}=\frac{e^{u_{x, i}}}{\sum_{x} e^{u_{x, i}}}
$$

Agents then draw a random number that will determine the mode they choose, based on $p_{x, i}$. This is to overcome the problem that notwithstanding the fact that logit's assignment of modes is probabilistic, agents are integral and need to be assigned a single mode for simulation purposes. For example, an agent who has a $75 \%$ probability of driving based on the logit model above would be assigned a 
single mode, and there would be a $75 \%$ probability that that mode would be the automobile.

3.3.2. Way-finding: Transit, car drivers, and cyclists only move on street cells. Pedestrians move only on sidewalks and across intersections. As mentioned above, our model does not explicitly consider the interactions between street, bike and pedestrian traffic within the neighborhood, where congestion is assumed to be low. We focus instead on interactions that could potentially feed back into mode choice, primarily those encouraging walking and biking through an increased sense of community surveillance. Commuters and transit vehicles follow a simple way-finding algorithm: (a) they determine the adjacent cell closest to their destination, excluding the cell from which they previously moved, (b) they move to that new cell, and (c) they repeat until they reach their destination.

Commuters walking to transit move to the CTA station, bus stop, or shuttle stop closest to their home cell. In the latter cases, when they reach their bus or shuttle stop they wait until their form of transit reaches an adjacent cell. Non-loop walking commuters move to a randomly selected cell in the neighborhood.

Buses move in straight lines starting furthest from the loop. Shuttles go from their starting locations in the corners of the landscape toward the train station at the center. When buses and shuttles go by their respective stops, they board any commuters waiting at the stop.

Loop commuters driving and biking all the way move toward the Loop-exit cell. NonLoop drivers are not explicitly modeled, since they do not affect safety feedback of other Loop commuters. Loop commuters biking to the train move to a cell adjacent to the train station. Non-Loop cyclists move toward one of the four neighborhood exits or to a randomly selected road cell in the neighborhood with equal probability.

Commuting beyond the neighborhood exit points and CTA stations is implicit, i.e., it affects mode choice via estimated commuting times (Table 1).

3.3.3. Safety Feedback: We assumed that as non-driving agents see other non-drivers along their commute, they feel safer and more inclined to walk or bike. Our model implements this assumption by updating the safety feedback score $\left(f_{x, i}\right)$ for Loop commuters according to the number of agents they come across that are walking, biking, or waiting for transit during their commute each day. They then use the updated score to choose the mode the next day (see section 0). Because there is little empirical data to support a specific implementation of this feedback mechanism, we did not have a basis to formulate a function linking the number of people encountered and associated perception of safety. Instead, we assumed two thresholds of satisfaction (low and high) that correspond to two general levels of pedestrian and cyclist presence that commuters would be aware of, and that would feed back into their perceived safety scores.

At the start of every minute all moving Loop commuters count the number of other agents walking, biking, or waiting for transit within one block ahead of them. Loop commuting pedestrians waiting at transit stops look one block all around them (Figure 6). If at least 30 agents are encountered, a higher satisfaction threshold is reached. If the agent counts at least 10 other non-drivers, but less than 30 , a lower satisfaction threshold is met. At the end of the day, agents calculate the proportion of time during the commute that each satisfaction threshold was reached and update the safety feedback variable as follows:

$$
f_{i, t 1}=1 \frac{t_{h, i}+0.5 \quad t_{l, i}}{t_{i}}
$$

where: 
$t_{, i}=$ agent $i$ 's time of exposure to the built environment in mode $x$;

$t_{h, i}=$ agent $i$ 's time of exposure in which the higher satisfaction threshold was met;

$t_{l, i}=$ agent $i$ 's time of exposure in which the lower satisfaction threshold was met.

Agents only save the score for the last day.

(a)

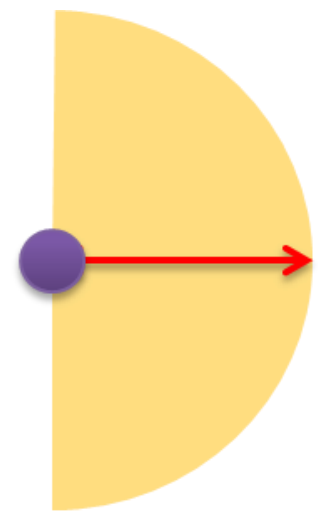

(b)

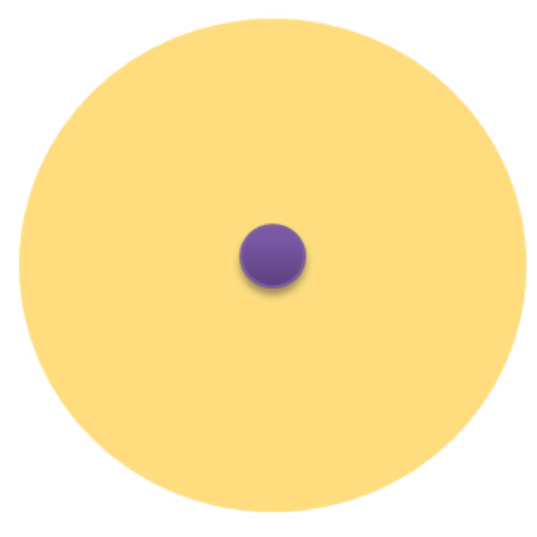

Figure 6. Viewshed for a) Pedestrians and Cyclists in Transit, and (b) for Pedestrians Waiting at Transit Stops (Commuter in Purple, Red Arrow = 1 Block)

Table 1. Default Model Paramaters

\begin{tabular}{|c|c|c|c|c|c|c|}
\hline \multirow{2}{*}{$\begin{array}{l}\text { Level of } \\
\text { Parameter }\end{array}$} & \multirow{2}{*}{\multicolumn{2}{|c|}{ Parameter }} & \multicolumn{4}{|c|}{ Base Value } \\
\hline & & & Pilsen & Cicero & Skokie & Evanston \\
\hline \multirow{23}{*}{$\begin{array}{l}\text { Global/ } \\
\text { Neighbor } \\
\text { hood }\end{array}$} & \multicolumn{2}{|c|}{ Driving speed $(\mathrm{km} / \mathrm{h})$} & 26.6 & 38.2 & 36.4 & 34.8 \\
\hline & \multicolumn{2}{|c|}{ Walking speed $(\mathrm{km} / \mathrm{h})$} & \multicolumn{4}{|c|}{4.8} \\
\hline & \multicolumn{2}{|c|}{ Biking speed $(\mathrm{km} / \mathrm{h})$} & \multicolumn{4}{|c|}{17.5} \\
\hline & \multicolumn{2}{|c|}{ Shuttle speed $(\mathrm{km} / \mathrm{h})$} & \multicolumn{4}{|c|}{24.1} \\
\hline & \multicolumn{2}{|c|}{ Bus speed $(\mathrm{km} / \mathrm{h})$} & \multicolumn{4}{|c|}{13.6} \\
\hline & \multicolumn{2}{|c|}{$\begin{array}{l}\text { Bus and train headway } \\
\text { (minutes) }\end{array}$} & \multicolumn{4}{|c|}{$8^{*}$ see section 0 for Evanston calibration } \\
\hline & \multicolumn{2}{|c|}{ Shuttle headway (minutes) } & \multicolumn{4}{|c|}{3} \\
\hline & \multicolumn{2}{|c|}{ Gas price (\$ per gallon) } & \multicolumn{4}{|c|}{4} \\
\hline & \multicolumn{2}{|c|}{ Shuttle fare $(\$)$} & \multicolumn{4}{|c|}{0} \\
\hline & \multicolumn{2}{|c|}{ Bus fare to Loop $(\$)$} & 2.25 & 2.25 & $\begin{array}{l}\text { southbound: } \\
2.25 ; \\
\text { eastbound: } \\
4.00 \\
\end{array}$ & 2.25 \\
\hline & \multicolumn{2}{|c|}{ Train fare to Loop $(\$)$} & \multicolumn{4}{|c|}{2.25 (see Section 0 for Evanston calibration) } \\
\hline & \multicolumn{2}{|c|}{ Automobile fuel economy (mpg) } & \multicolumn{4}{|c|}{22.6} \\
\hline & \multicolumn{2}{|c|}{$\begin{array}{l}\text { Bus travel time from } \\
\text { neighborhood to Loop } \\
\text { (minutes) }\end{array}$} & $\begin{array}{c}\text { northbound: } \\
31 ; \\
\text { eastbound: } \\
31 \\
\end{array}$ & $\begin{array}{c}\text { northbound: } \\
49 ; \\
\text { eastbound: } \\
61 \\
\end{array}$ & $\begin{array}{l}\text { southbound: } \\
\text { 86; eastbound: } \\
96\end{array}$ & $\begin{array}{c}\text { southbound: } \\
77 ; \\
\text { eastbound: } \\
80 \\
\end{array}$ \\
\hline & \multirow{2}{*}{\multicolumn{2}{|c|}{$\begin{array}{l}\text { Train travel time from } \\
\text { neighborhood station to Loop } \\
\text { (minutes) }\end{array}$}} & 25 & 38 & 59 & $48^{*}$ \\
\hline & & & \multicolumn{4}{|c|}{ * see section 0 for Evanston calibration } \\
\hline & \multirow{2}{*}{$\begin{array}{l}\text { Distance to } \\
\text { Loop }(\mathrm{km})\end{array}$} & Driving & 5.96 & 14.00 & 26.07 & 23.17 \\
\hline & & Biking & 5.96 & 12.87 & 29.29 & 23.33 \\
\hline & \multirow{6}{*}{$\begin{array}{l}\text { Total } \\
\text { transfers }\end{array}$} & Walk to train & 0 & 0 & 1 & 0 \\
\hline & & Drive to Loop & 0 & 0 & 0 & 0 \\
\hline & & Bike to Loop & 0 & 0 & 0 & 0 \\
\hline & & Bike to Train & 1 & 1 & 2 & 1 \\
\hline & & $\begin{array}{l}\text { Shuttle to train } \\
\text { to Loop }\end{array}$ & 1 & 1 & 2 & 1 \\
\hline & & Bus to Loop & $\begin{array}{c}\text { northbound: } \\
1 ;\end{array}$ & $\begin{array}{c}\text { northbound: } \\
2 ;\end{array}$ & $\begin{array}{l}\text { southbound: } 2 \text {; } \\
\text { eastbound: } 2\end{array}$ & $\begin{array}{c}\text { southbound: } \\
1 ;\end{array}$ \\
\hline
\end{tabular}




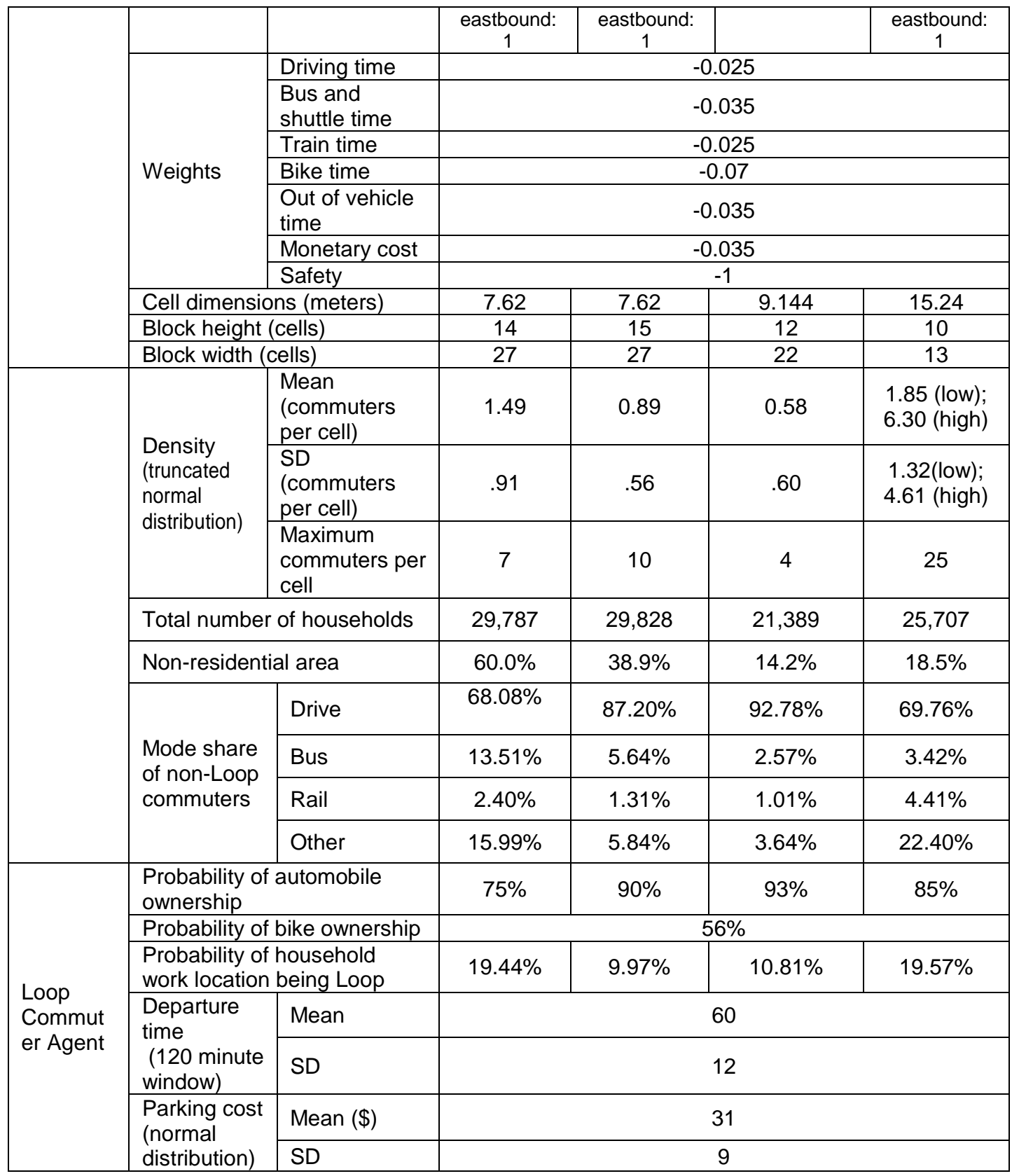

\section{Understanding and Calibrating the Model}

Our model is designed to illustrate the ways in which the suggested landscape and transit improvements may promote shifts from driving to transit, cycling, or pedestrianism. It is not designed as an accurate forecasting tool. With this model we sought to recreate the general patterns of mode share observed in the four neighborhoods of reference, and to explain general patterns reported in the literature. We thus conducted two types of tests with our model. The first set of tests involved examining the impacts of some model assumptions on the results, to fine-tune the default values for model parameters. Once these were completed, we introduced neighborhood-specific modifications to the model to address the remaining discrepancies between simulations results and empirical data. These tests allowed us to better understand how the mechanisms in the model generated the resulting mode choice in each scenario. We describe these structural changes below. 


\subsection{General Calibration}

To validate our model, we tested its capacity to generate current observed mode shares as reported by RTAMS (Regional Transportation Authority Mapping and Statistics, 2012). The largest discrepancy to start with pertained to cycling; initial results suggested higher rates of biking than what is observed in our neighborhoods, due to its free cost and relatively favorable times (similar to transit). While this suggests there is a high potential for increases in bike use, existing barriers prevent this potential from being realized in the US, such as people's physical capacity and cultural attitudes, and supporting infrastructure both in the built environment and in the work environment facilities at work. In order to account for the discrepancy between modeled and actual cycling, we applied a biking penalty of -1 , a fixed amount that lowers the bike and bike-to-train utilities. Adding this bike penalty resulted in lower shares compared to reported data, but allowed for biking to appear as a choice and at higher levels in neighborhoods closer to the Loop, which is consistent with observations.

\subsection{Neighborhood-specific Calibration}

While the modeling results were reasonable for biking in all neighborhoods, the model still showed discrepancies greater than $10 \%$ compared to the RTAMS data for bus, train and driving in several neighborhoods. The differences between modeled results and empirical data formed the basis for a new round of calibration, based on possible explanations for the discrepancies in each neighborhood. In Pilsen, bus ridership data is higher than the share produced by our model. We thus included a greater number of bus lines to the Loop, reflecting the greater bus connectivity due to its proximity to the downtown area. Some of these additional routes also offered faster times than other lines, and no transfers (Figure 7). Once taking the bus became more convenient for Pilsen agents, results came to within roughly eight percentage points of the RTAMS data (Table 2).

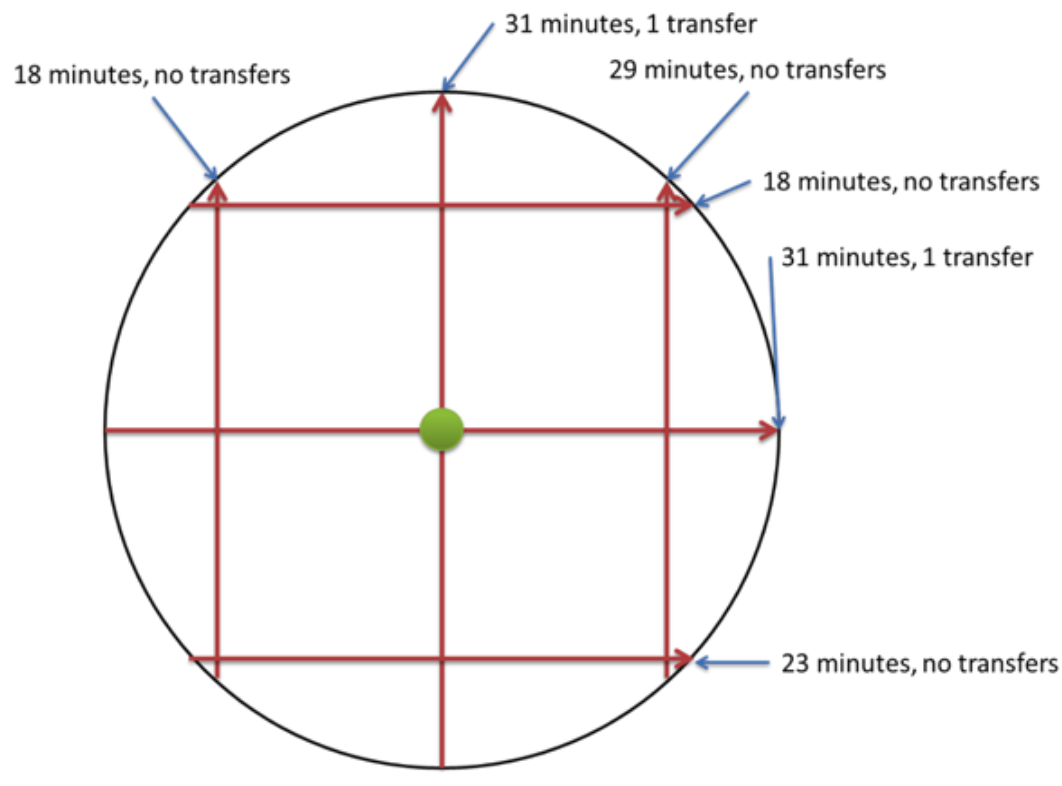

Figure 7. Revised Pilsen Bus Network (Bus Lines in Red; CTA Station in Green)

In Evanston, train ridership is higher than the initial model produced. A possible explanation is the presence of a regional commuter Metra train station immediately adjacent to the Davis CTA station, which greatly reduces commuting times to the Loop 
due to express services during rush hour. We thus revised the model parameters in Table 1 to account for the quicker Metra times from the station to the Loop (26.5 minutes) but greater headway (11 minutes) and the higher Metra fare (\$4.25). While additional drivers switched to the train, train use was still nine percentage points lower than the empirical data and driving seven percentage points too high, prompting us to further revise the model, this time to represent the extensive bus network shuttling commuters to the Davis station. In a sense, Evanston already has an established network with a similar function to the proposed driverless shuttles. The base scenario for Evanston thus includes shuttles going to the train station running every eight minutes like CTA buses, instead of three minutes like the proposed shuttle, and with the regular CTA bus fare. With the combined bus to train and the Metra data setups, overall results came within 7\% of the RTAMS data (Table 2).

Table 2. Comparison between Final Calibration and Empirical Data on Percentage Mode Share for the Four Chicago Neighborhoods (Source: Regional Transportation Authority Mapping and Statistics, 2012). Note: Train includes Walk to Train, Bike to Train and Bus to Train; Bike RTAMS Data Corresponds to "Other" Category, which includes Biking

\begin{tabular}{|c|c|r|r|r|r|}
\hline \multicolumn{2}{|c|}{ Mode } & \multicolumn{1}{c|}{ Pilsen } & \multicolumn{1}{c|}{ Cicero } & \multicolumn{1}{c|}{ Skokie } & \multicolumn{1}{c|}{ Evanston } \\
\hline \multirow{2}{*}{ Train } & Model & 31.6 & 33.0 & 31.6 & 69.0 \\
\cline { 2 - 6 } & RTAMS data & 24.6 & 32.0 & 39.5 & 65.4 \\
\hline \multirow{2}{*}{ Bike } & Model & 2.1 & 0.6 & 0.01 & 0.04 \\
\cline { 2 - 6 } & RTAMS data & 4.8 & 2.2 & 0.6 & 2.3 \\
\hline \multirow{2}{*}{ Bus } & Model & 30.6 & 10.3 & 5.3 & 4.3 \\
\cline { 2 - 6 } & RTAMS data & 32.6 & 9.8 & 1.7 & 1.8 \\
\hline \multirow{2}{*}{ Drive } & Model & 35.6 & 56.2 & 63.0 & 26.7 \\
\cline { 2 - 6 } & RTAMS data & 38.0 & 56.0 & 58.1 & 32.8 \\
\hline
\end{tabular}

\section{Scenarios and Simulation Results}

With the baseline case defined, we used the model to test a range of policy scenarios to identify the isolated and combined effects of streetscape improvements, monetary disincentives, and the provision of shuttles to the neighborhood transit station. Streetscape improvements are abstractly defined in two levels (Figure 7), lower and ideal. The lower level corresponds to non-motorized transportation improvements only (e.g., providing crosswalks, bike lanes). Ideal streetscape improvements would add amenities to the nonmotorized transportation improvements (e.g., landscaping, streetscape furniture, information kiosks). Improvements are activated five days into a simulation, so that an initial equilibrium state is established; the final results can be attributed solely to the improvements. In this section, we show only results for the ideal level of streetscape improvements to examine the effect of the best possible scenario. Shuttle scenarios include the enhanced shuttle service to the transit stations. Finally, monetary incentives are represented as reduced transit fares ( $\$ 0.25$ for bus or train), increased gas price similar to European cities ( $\$ 9$ per gallon), and increased parking costs (additional \$20 to assigned baseline).

We organize the analysis of our results around two main questions:

1. What kinds of policies are most effective at reducing driving? In particular, under what conditions are shuttles most effective at reducing driving?

2. How do policy effects vary with distance from transit station?

\subsection{Policy Effectiveness}

Overall, the shuttles and urban design improvements in combination were quite effective at shifting downtown commuters to non-automotive modes. This was most 
pronounced outside of Evanston, with a reduction in auto use relative to the base case was between 12 and 21 percentage points (Table 2, Figure 8). With a current effective local shuttle service provided by CTA buses and a more pedestrian-oriented environment, Evanston showed lower improvements. Reductions in driving were considerable when the three sets of changes - urban design improvements, cost scenarios, and shuttles-were considered in combination. In this maximalist scenario, reductions in driving of between 23 and 40 percentage points among downtown drivers were realized for most neighborhoods, and an 18 percentage point reduction in Evanston. Policies to raise the cost of driving relative to other modes are notoriously difficult to implement politically; notwithstanding this challenge, results presented here highlight the importance of these measures for maximum effect and provide some basis for optimism regarding their potential impact.

Less dense neighborhoods (Cicero and Skokie) were more sensitive to higher parking costs, streetscape improvements and shuttle service than the denser neighborhoods (Pilsen and Evanston), suggesting that where environments are more urban in character with these elements present to some extent, there may be fewer gains to be realized.

Evanston is the least responsive to shuttle services, due to its high level of bus service towards the CTA and Metra stations. Streetscape improvements have a larger effect, but smaller than in other neighborhoods due to the high density around the stations and shorter distances from the Lake, which decreases the time of exposure to the street environment. The higher density in central Evanston would also explain why shuttle service and street improvements seem to serve different populations: shuttles would likely target residents living further away but close to shuttle routes, while streetscape improvements target commuters who have to spend more time walking across the neighborhood. As a result, the effects of applying each policy independently add up in the combination scenario. Increasing driving costs, on the other hand, duplicates some of the effect of combining streetscape improvements and shuttle service, but by itself accounts for a larger share of the driving reductions. Such policy would therefore be most effective in this kind of neighborhood. The extensive bus coverage, higher density and fragmented urban fabric in Pilsen likely reduce the impact of providing shuttles. Combining this transit option with streetscape improvement, however, helps overcome the barriers of discontinuous residential areas. Such combination has a similar effect to increasing driving costs, while combining all three policies suggests overlapping target populations. Cost policies could focus on lower fares, with streetscape improvements to further reinforce a shift towards transit.

Skokie's and Cicero's greater response to policy combinations (costs, streetscape improvements and shuttle service) compared to other neighborhoods may be explained by low density, lower access to the Loop, and thus fewer transportation options that result in higher driving mode shares to start with (Table 2). In this context, location with respect to the transit station and shuttle routes likely has a greater influence on mode choice, so that diverse policies may more effectively complement each other as they target different locations within the neighborhood. For example, greater pedestrian and cyclist traffic is most likely to be accomplished by streetscape improvements close to the train station and shuttle stops because at low densities pedestrian and cyclist presence is more noticeable at the confluence of neighborhood trips. Shuttle services, on the other hand, are more likely to influence agents living farther away from the station, but only if they live close to a transit stop; in a low-density neighborhood, accessibility is reduced. Those who cannot adequately be served by the shuttle because they are far from a shuttle stop and do not live close enough to the station to use transit regularly might shift from driving only if the latter becomes too expensive. Cicero's fragmentation (and thus lower accessibility in some areas) might explain the lower reductions in driving brought about by scenarios increasing driving cost, relative to Skokie's continuous urban fabric as represented in the model. In higher-density neighborhoods with greater transportation choices, there is less 
geographical differentiation, so that different kinds of policies would influence overlapping populations. Combining policies, therefore, would result in redundant rather than complementary effects.

We anticipated that streetscape and transportation improvements would generate the positive feedback of pedestrian and biking presence in the streets to support a widespread shift in mode share from driving to other modes. This did not happen, however. Reasons for the low impact of safety feedback can be attributed to the mechanisms that we used in our model to represent this influence. We built these mechanisms based on simplifying working assumption about how we expected commuters to respond to the presence of people on the streets, and to improvements in the built environment. Our model is a first attempt to make explicit the assumptions of how pedestrians and cyclists may assess their environment. There is little data to support these assumptions, however, particularly about the weights we attributed to each factor in the safety feedback. We conducted sensitivity tests to see the effect of these assumptions, which showed that increasing the concern for safety would only increase driving, where safety is not a concern.

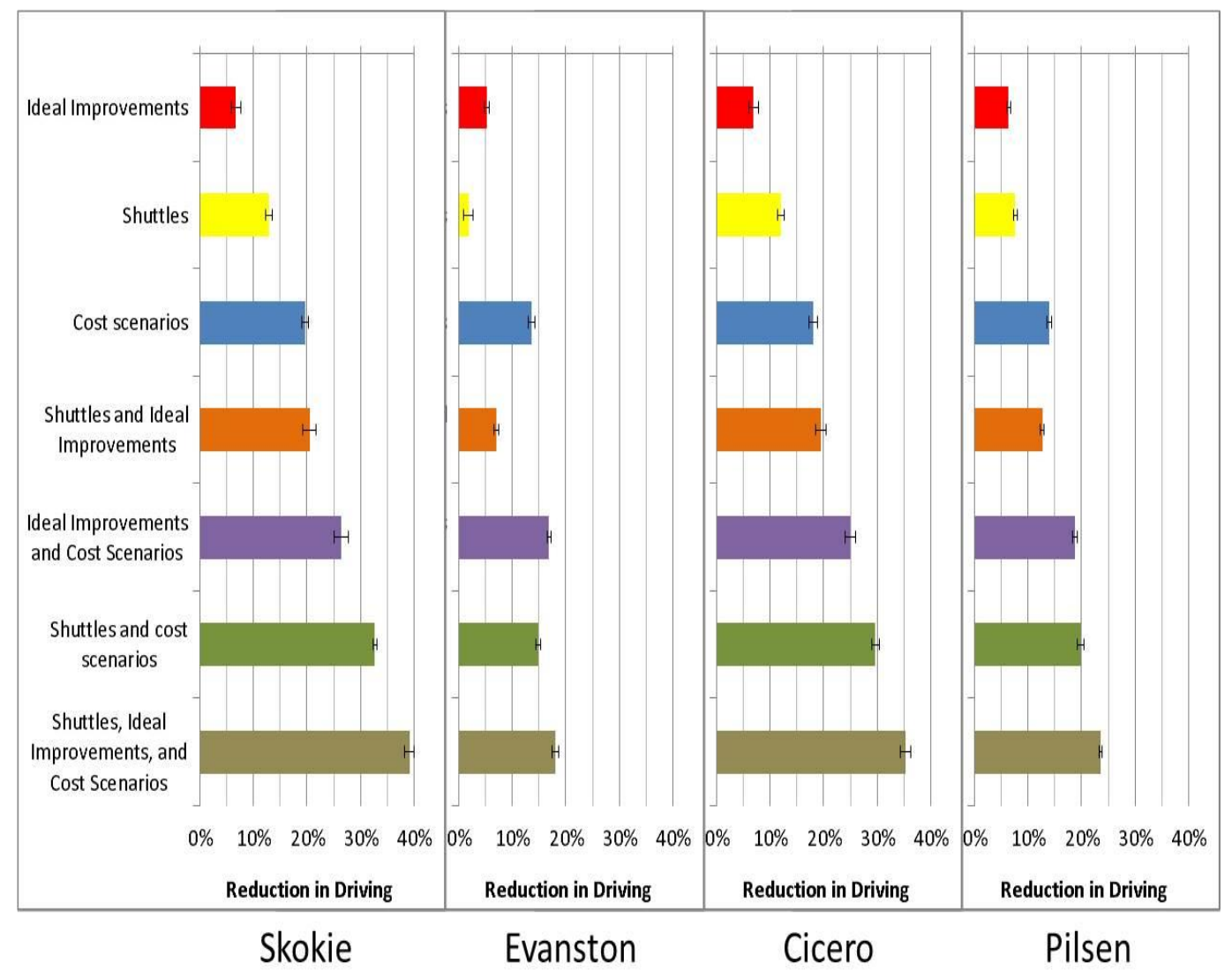

Figure 8. Reductions in Driving Share under Different Improvement Scenarios in (a) Skokie, (b) Evanston, (c) Cicero, and (d) Pilsen 


\subsection{Distances from Station}

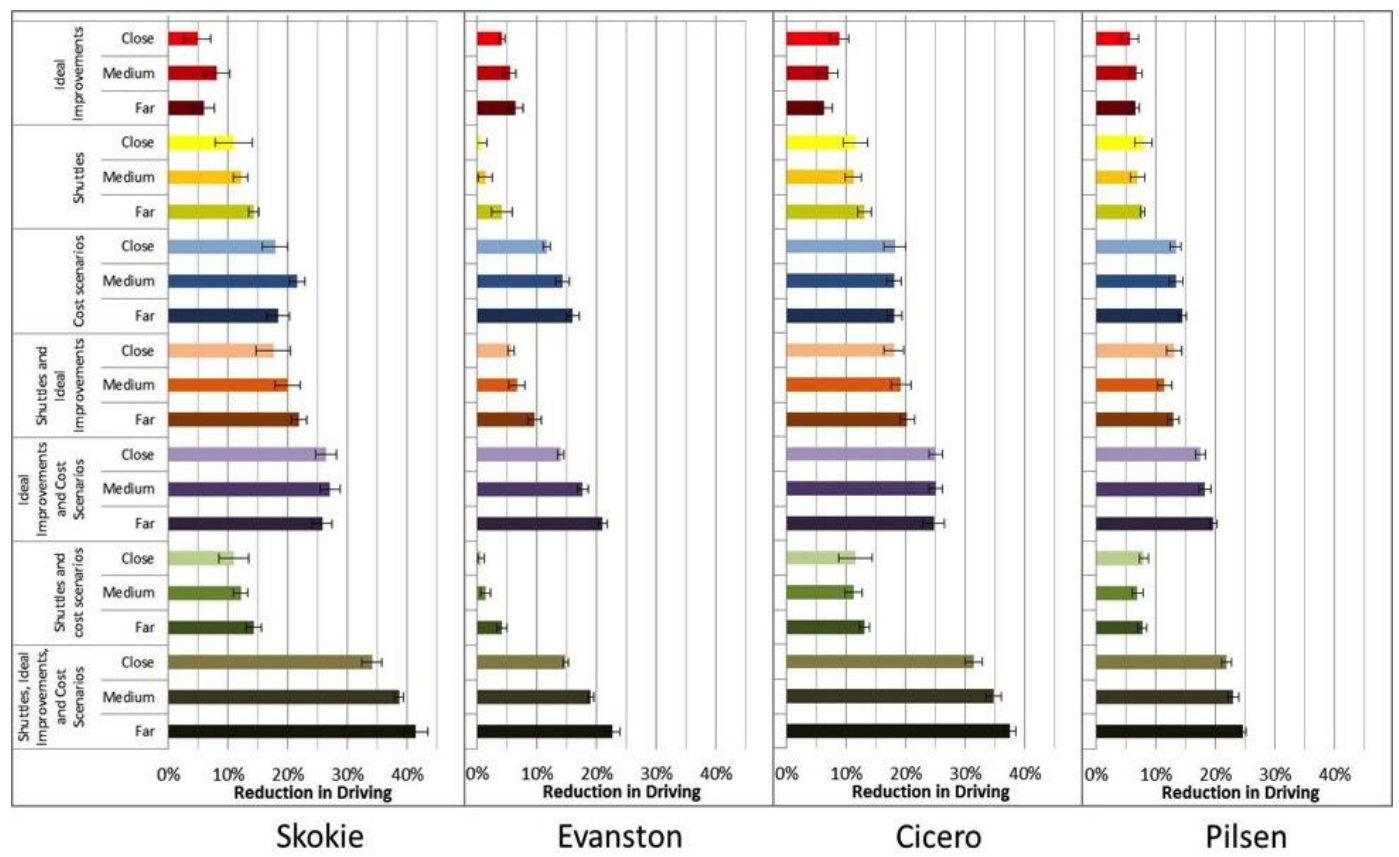

Figure 9. Reductions in Driving Share by Improvement Scenarios and Distance from the Station

Our model allows us to disaggregate results based on location with respect to the transit station at the center of each simulated neighborhood. We examine the reductions in driving for agents located at 0 to 0.5 mile, 0.5 to 1 mile, and 1 to 1.5 miles from the station. Simulations suggest that living closer to the station encourages alternative modes of transportation in all neighborhoods, while driving is favored the further away commuters live from the transit station. Policy combinations promote greater shifts from driving in commuters living farther away from the station. The exception is Pilsen, which presents higher accessibility due to its proximity to the Loop and its wider bus coverage (Figure 9). Examining independent policies provides additional insights regarding their locational effect in the different neighborhood types.

Improving the streetscape has a more widespread effect on Pilsen, likely as a consequence of broader bus connectivity, land use fragmentation and proximity to the Loop; improvements can have a direct impact attracting bus riders and cyclists throughout the neighborhood. In Evanston, the high connectivity close to the station makes the streetscape improvement less relevant than further out. Conversely, in Cicero the low density and fragmentation prevents the streetscape improvement from reducing ridership at greater distances from the station. In Skokie, we see a similar declining trend as distance increases, with the exception of lower driving reductions close to the station. A possible explanation is that those commuters closer to the station are already taking transit, while those living further out are captive drivers.

Except for Evanston, shuttles contributed to widespread decline in driving. Overall, effects were more variable for commuters living close to the station, suggesting that final choice may be more influenced by randomness due to initial choices and location. More systematic decreases in driving are obtained for commuters living further away from the station. In Pilsen, the effect of distance is reduced by the presence of buses.

Cost policies have a widespread effect in Cicero and Pilsen, whose proximity to the Loop might provide more options when driving expenses increase. Evanston's commuters 
closer to the train station are already well served by a bus and transit system, so the costs of driving are felt more by those living far from the station, who are thus encouraged to shift due to the better access to transit. In Skokie, on the other hand, the transit options are not as good, so that shifts are greater in commuters living closer to the station, but those living far from the station must depend on driving.

The combination of policies produces the greatest differential impact in Evanston and Skokie, incentivizing relatively more commuters living far from the station to reduce driving. The greater distances to the Loop reduce the options for those living far from the station, so that improvements encourage shifts and higher costs further discourage driving. Based on the observations above, however, the greater limitations in Skokie result in greater number of captive drivers far from the station. The effects of policy combinations are more widespread in Cicero and Pilsen, rather than localized by distance to the station. Cicero's proximity to the Loop allows for driving to be a viable option until driving costs increase, in which case complementary improvements support a shift to transit. Pilsen's high bus connectivity and its proximity to downtown increase accessibility by transit and bicycle, reducing the influence of distance to a neighborhood station.

\section{Policy Implications and Future Work}

In its current form, our model recreates mode shares similar to the ones observed in the four neighborhoods of reference, and provides a reasonable explanation for these values and justification of the parameter values chosen. With this in place, the model allowed us to conduct an initial investigation about the potential effectiveness of a service that does not yet exist, and to understand the influence of decision-making mechanisms for which data is not available. Potentially, our model could be used to transfer the lessons learned here, both from understanding the effects on the four neighborhoods simulated, and from the ability of the model to represent other neighborhoods defined by their land use and density, location with respect to a central business district, and income level.

Our model suggests that the policies explored could effectively reduce driving and shift commuters to other forms of transportation. Shuttles have a significant impact and may prove to be robust policies in low-density neighborhoods that have few transportation alternatives to downtown areas. In areas already offering a good coverage and reliable provision of bus service to train stations, shuttles would be redundant and less effective. If bus service, however, is unreliable, a dedicated shuttle service may support significant shifts to transit. These shifts may be reinforced when streetscape improvements target areas close to shuttle stops. Policies that increase the cost of driving can reinforce the benefits of improving the provision of public transportation, particularly if limited space in denser neighborhoods requires eliminating on-street parking to allow for bike and shuttle lanes. Our scenarios are likely to have a wider impact when considering the larger commuter population traveling to destinations other than downtown.

While the positive feedback of pedestrian and cyclist presence did not have the impact we had anticipated, their influence could potentially help shift the pattern towards greater use of alternative modes if drivers, for example, are also discouraged from driving as biking and pedestrian presence increases. It will become relevant, then, to model drivers explicitly. Alternatively, transportation and streetscape quality and people's presence may have different kinds of impact; once a minimum level of safety is reached, further physical improvements and street activity may not add to the perception of safety but to the perception of attractiveness for pedestrian and bike use. Future steps involve implementing these concepts into model mechanisms and appropriate parameter values to examine how to promote a more significant mode shift away from driving in response to streetscape and transportation improvements. This insight suggests that if safety were an issue, improvements alone are unlikely to promote the desired shifts from driving. 
Our model also provides a framework for empirical data collection and analysis. A household survey in our four Chicago neighborhoods of reference is now complete, and the data is being analyzed through the lens of the model mechanisms. A stated preferences model is being developed based on this data, which will provide updated, empirically estimated parameters for the agent-based model. Robust implications will be derived from coincident outputs of both modeling approaches, while discrepancies will suggest directions of further research on the behavioral potential impacts of transportation policy. The survey data will also reveal relationships between commuter attributes, which will allow us to create typologies of agents, related preference values and location. In particular, we hope that data analysis will shed light on the mechanisms involved in pedestrians' and cyclists' perception of safety and how it influences mode choice.

Mixed-use neighborhoods contain attractions for commuters on their way to work. Our current version of the model does not allow commuters to make stops during their trip. Including this possibility will involve a form of activity-based modeling, where travel decisions will be based on activities and schedules. The household survey will provide initial data for this purpose. In concert, the various sets of models will allow further investigation into the dynamics of mode choice in significantly altered environments of urban transportation and land use.

\section{Acknowledgments}

This research was conducted with funding from the Federal Highway Administration, USA. We are grateful to Bob Ferlis for his guidance and feedback, and to two anonymous reviewers for their insightful comments and support.

\section{References}

[1] L. Quadrifoglio and S. Chandra, "Evaluating the Effect of Street Network Connectivity on First/Last Mile Transit Performance: Texas Transportation Institute", Texas A\&M University System, (2011).

[2] Federal Transit Administration. Table 14 Retrieved 7/27, 2012, from http://www.ntdprogram.gov/ntdprogram/pubs/dt/2010/excel/DataTables.htm, (2010).

[3] A. M. Agrawal, M. Schlossberg and K. Irvin, "How Far, by Which Route and Why? A Spatial Analysis of Pedestrian Preference", Journal of Urban Design, vol. 13, no. 1, (2008), pp. 81-98.

[4] B. Saelens, B. and S. Handy, "Built Environment Correlates of Walking: A Review", Medicine \& Science in Sports \& Exercise, vol. 40, no. 7S, (2008), pp. S550-S566.

[5] V. Mehta, "Look Closely and You Will See, Listen Carefully and You Will Hear: Urban Design and Social Interaction on Streets", Journal of Urban Design, vol. 14, no. 1, (2009), pp. 29-64.

[6] N. Estupiñan and D. Rodríquez, "The Relationship between Urban Form and Station Boardings for Bogotá's BRT”, Transportation Research Part A, vol. 42, (2008), pp. 296-306.

[7] D. Rodríquez, N. Estupiñan and B. Elizabeth, "The relationship between segment-level built environment attributes and pedestrian activity around Bogota's BRT stations", Transportation Research Part D: Transport and Environment, vol. 14, no. 7, (2009), pp. 470-478.

[8] R. Buehler and J. Pucher, "Cycling to Work in 90 Large American Cities: New Evidence on the Role of Bike Paths and Lanes", Transportation, vol. 39, no. 2, (2012), pp. 409-432.

[9] J. Pucher, J. Dill and S. Handy, "Infrastructure, Programs and Policies to Increase Bicycling: An International Review", Preventive Medicine, vol. 50, no. S1, (2010), pp. S106-S125.

[10] Regional Transportation Authority Mapping and Statistics. Work Trip Flows. Retrieved 4/6, 2012, from http://www.rtams.org/rtams/ctppHome.jsp, (2012).

[11] L. Zhang and D. Levinson, "An Agent-Based Approach to Travel Demand Modeling: An Exploratory Analysis", Journal of the Transportation Research Board(1898), (2004), pp. 28-38.

[12] M. Batty, "Cities and Complexity: Understanding Cities with Cellular Automata", Agent-Based Models, and Fractals. Cambridge: MIT Press, (2005).

[13] M. Iacono, D. Levinson and A. El-Geneidy, "Models of Transportation and Land Use Change: A Guide to the Territory", Journal of Planning Literature, vol. 2, no. 4, (2008), pp. 323-340.

[14] Y. Lu, K. Kawamura and M. L. Zellner, "Exploring the Influence of Urban Form on Work Travel Behavior with Agent-Based Modeling", Transportation Research Record: Journal of the Transportation Research Board(2082), (2008), pp. 132-140. 
[15] S. McDonnell and M. L. Zellner, "Exploring the Effectiveness of Bus Rapid Transit: A Prototype Agent-Based Model of Commuting Behavior", Transport Policy, vol. 18, no. 6, (2011), pp. 825-835.

[16] U. Wilensky, "NetLogo. Evanston, IL: Center for Connected Learning and Computer-Based Modeling", Northwestern University. Retrieved from http://ccl.northwestern.edu/netlogo/, (1999).

[17] Cook County. Cook County GIS MapCenter Retrieved 4/3, 2011, from https://secure.cookcountyil.gov/gis/metadata.php, (2001).

[18] U. S. Census Bureau. H3 - Occupancy Status Retrieved 9/8/2012 from http://factfinder2.census.gov/faces/nav/jsf/pages/index.xhtml, (2010).

[19] goroo: Powered by the Regional Transportation Authority Retrieved 8/1, 2012, from http://goroo.com/goroo/index.htm, (2012).

[20] Google Maps Retrieved 8/2, 2012, from https://maps.google.com/, (2012).

[21] Chicago Transit Authority. Route \& System Guides Retrieved 8/2, 2012, from http://www.transitchicago.com/riding_cta/systemguide/default.aspx, (2012a).

[22] Pace Suburban Bus. Fare Information Retrieved 8/2, 2012, from http://www.pacebus.com/sub/schedules/fare_information.asp, (2012).

[23] Chicago Transit Authority. System Brochure Map Retrieved 8/2, 2012, from http://www.transitchicago.com/assets/1/brochures/ctaSystemMapBrochure.pdf, (2012b).

[24] D. Royal and D. Miller-Steiger, "National Survey of Bicyclist and Pedestrian Attitudes and Behavior; Volume II: Findings Report. In U. S. Department of Transportation \& National Highway Traffic Safety Administration (Eds.), (2008).

[25] Federal Highway Administration. 2007 Transportation Profiles. Census 2000 and 2005-2007 ACS $\quad$ Retrieved 7/17, 2012, from http://www.fhwa.dot.gov/planning/census_issues/american_community_survey/products/2007_tr ansportation_profiles/index.cfm, (2011).

[26] R. Moore, "Parking Not Getting any Cheaper - and Unlikely to Do So", Colliers International, (2010).

[27] Federal Highway Administration, Travel Model Validation and Reasonableness Checking Manual, Second Edition, (2010).

[28] National Cooperative Highway Research Program. Travel Demand Forecasting:Parameters and Techniques, Report 716. Washington, DC: Transportation Research Board, (2012).

[29] Bureau of Transportation Statistics. Table 4-23: Average Fuel Efficiency of U.S. Light Duty Vehicles Retrieved 3/20, 2011, from http://www.bts.gov/publications/national_transportation_ statistics/html/table_04_23.html, (2011).

[30] S. J. Chowdhury and A. Ceder, "Interchange Attributes Influencing Public-Transport User's Intention to Use Routes with Transfers", (2012).

[31] N. H. Wilson and J. Ferreira, "Improving the Understanding of Transfer Behavior in Urban Public Transport Networks: New England University Transportation Center", Massachusetts Institute of Technology, (2006).

[32] J. Jacobs, "The Death and Life of Great American Cities", New York: Random House, ISBN 0679-60047-7, (1961).

[33] A. Loukaitous-Sideris, "Is it Safe to Walk? Neighborhood Safety and Security Considerations and their Effects on Walking", Journal of Planning Literature, vol. 20, pp. 219-232, (2006).

\section{Authors}

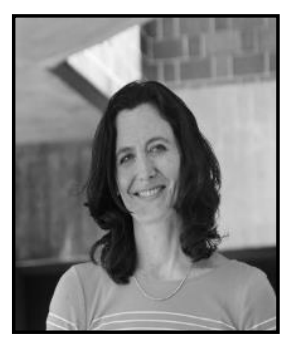

Moira Zellner is an associate professor in the Department of Urban Planning and Policy and a research assistant professor in the Institute for Environmental Science and Policy at UIC. Having completed her undergraduate degree in ecology in Argentina, she pursued graduate studies in urban and regional planning and in complex systems at the University of Michigan. Her research involves assessing the environmental impacts of urbanization and exploring how to enhance the sustainability and resilience of urban areas through policy and behavioral change. Her work also examines the applicability of complexity theory and complexity-based models to policy exploration and social learning. 

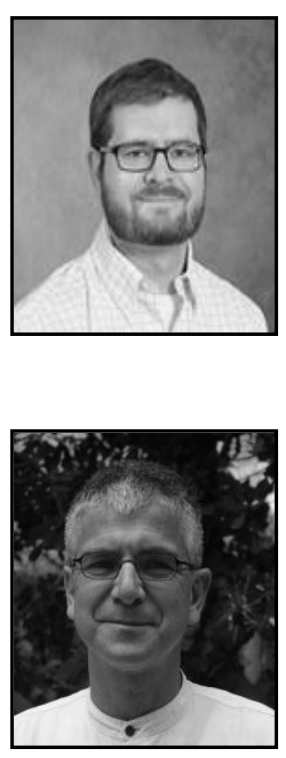

Yoram Shiftan is an Associate Professor of Civil and Environmental Engineering in the Technion, and the previous Head of the Transportation and Geo-Information Department. Prof. Shiftan received his $\mathrm{Ph} . \mathrm{D}$. from MIT, and at Technion teaches and conducts research in travel behavior with a focus on activity-based modeling and response to policies, the complex relationships between transport, the environment and land use, transport economics and project evaluation. He is the editor of Transport Policy and the chair of the International Association of Travel Behavior Research (IATBR). He has published dozens of papers and co-edited the books 'Transportation Planning' in the series of Classics in Planning, and "Transition towards Sustainable Mobility, The Role of Instruments, Individuals and Institutions".

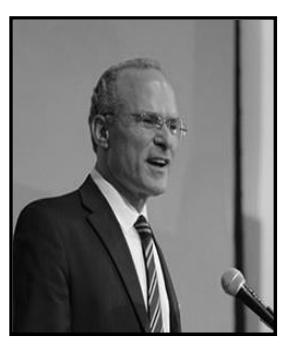

Jonathan Levine is the Emil Lorch Professor of Architecture and Urban Planning in the Taubman College of the University of Michigan. He received a Ph.D. in City and Regional Planning from UC Berkeley. Prof. Levine's research centers on the potential and rationales for policy reform in transportation and land use. His current work focuses on the transformation of the transportation and land-use planning paradigm from a mobility to an accessibility basis an includes a number of funded projects and a book in preparation jointly with Professor Joe Grengs. He is also interested in the design of institutions for emerging transportation systems - which may be based in large measure on autonomous electric vehicles - to serve metropolitan-accessibility goals. He is the author of Zoned Out: Regulation, Markets, and Choices in Transportation and Metropolitan Land Use (Resources for the Future 2006), which argued for transportation and land-use policy reform on the basis of expansion of households' effective range of choices rather than proven modification of travel behavior. His research has been supported by organizations including the Federal Highway Administration, Environmental Protection Agency, Graham Environmental Sustainability Institute, Michigan Department of Transportation, Mineta Transportation Institute, Ann Arbor Transportation Authority, and SMART (Suburban Detroit Public Transit.

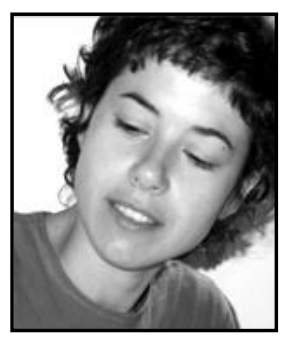

Maria Josefa Arquero is currently an Assistant Professor in Architecture and Urban Planning and Design in Taubman College, the University of Michigan. She holds degrees in Architecture, from the E.T.S.A.M., Polytechnic University, a master of Advanced Studies in Landscape Architecture from the E.T.H. 
Zurich, and a master of Landscape Architecture in Urban Design from the G.S.D., Harvard University. Her research, teaching and practice focus on the design, representation and use of public space both as environmental infrastructure, and as a field of experimentation to devise new forms of civic engagement. Her recent work in the city of Detroit and surrounding region interrogates the agency of the design and planning disciplines in territories under dynamics of urban contraction and sustained population loss. Other current academic collaborations look at the visualization of water dynamics in the Great Lakes region as a vehicle to better inform land use decisions. This line of research articulates the role of visual representation as a mode of inquiry and spatial thinking, a platform to enable design synthesis across geographies, scales and disciplinary cultures. 
International Journal of Transportation

Vol.4, No.1 (2016) 